Sir,

\section{Persistent central posterior capsule bulging after cataract extraction for posterior lenticonus}

Posterior lenticonus is a condition described as bulging of the posterior capsule and the underlying cortex often associated with lens opacity in the adjacent area. ${ }^{1,2} \mathrm{We}$ describe a case of posterior lenticonus that was treated with cataract extraction and intraocular lens (IOL) implantation. A persistent central bulging of the posterior capsule (forming an oval cavity between the IOL and the posterior capsule) was evident postoperatively.

\section{Case report}

A 25-year-old woman presented to our institute with diagnosis of congenital cataract in her left eye. Her best-corrected distance visual acuity (BCDVA) was 20/400 in her left eye with refraction of -8.00 $-8.00 \times 180$. Corneal keratometry was 44.91 diopters in the steep meridian $\left(104^{\circ}\right)$ and 41.94 in the flat meridian $\left(14^{\circ}\right)$, suggesting that refractive astigmatism was mainly of lenticular origin. The patient reported history of amblyopia treatment with occlusion during childhood. In slit lamp examination, the presence of posterior lenticonus with discoid opacification of the posterior pole was observed (Figure 1a). Axial length was $23.34 \mathrm{~mm}$ (IOL master, Carl Zeiss Meditec, Jena, Germany). Right eye was normal. The patient underwent cataract extraction and IOL implantation. The lens was aspirated through an anterior capsoulorhexis and a one-piece IOL was inserted in the capsular bag. Three months postoperatively the patient had uncorrected distance visual acuity 20/200 and BCDVA $20 / 160$ with refraction $+1.00-2.50 \times 10$. In slit lamp examination, the posterior capsule was in contact with the IOL in the entire posterior surface except from a central well defined round area that corresponded to the lenticonus, where the capsule was detached from the IOL, forming an oval cavity between the IOL and posterior capsule (Figure 1b). In 5-month follow-up findings were similar.

\section{Comment}

Posterior lenticonus is usually a unilateral or bilateral condition described as bulging of the posterior capsule and the underlying cortex. ${ }^{1-3}$ Management is with treatment of amblyopia and cataract surgery if needed. ${ }^{4}$ Cause of lenticonus is considered to be the thinning and bending of the posterior capsule that leads to progressive distortion of the lens fibers and cataract formation. ${ }^{2,5}$ In our case it seems that even after cataract extraction, the posterior capsule still preserved its preoperative configuration with a central well-defined bulging part. Surgeons should be informed about this post cataract finding as a sign of pre-existing posterior lenticonus (frequently accompanied by postoperative amblyopia) and distinguish it from other clinical entities with similar clinical findings (such as, postoperative capsular block syndrome).

\section{Conflict of interest}

The authors declare no conflict of interest.

\section{References}

1 Reese WS. Posterior lenticonus. Trans Am Ophthalmol Soc 1928; 26: 339-345.

2 Amaya L, Taylor D, Russell-Eggitt I, Nischal KK, Lengyel D. The morphology and natural history of childhood cataracts. Surv Ophthalmol 2003; 48: 125-144.

3 Russell-Eggitt IM. Non-syndromic posterior lenticonus a cause of childhood cataract: evidence for X-linked inheritance. Eye (Lond) 2000; 14: 861-863.

4 Cheng KP, Hiles DA, Biglan AW, Pettapiece MC. Management of posterior lenticonus. J Pediatr Ophthalmol Strabismus 1991; 28: 143-149; discussion 150.

5 Khalil M, Saheb N. Posterior lenticonus. Ophthalmology 1984; 91: $1429-1430,43 \mathrm{~A}$

GD Kymionis, GA Kontadakis, A Plaka and IG Pallikaris

Institute of Vision and Optics, University of Crete, Medical School, Heraklion, Greece

E-mail: kymionis@med.uoc.gr

Eye (2012) 26, 889; doi:10.1038/eye.2012.38;

published online 2 March 2012
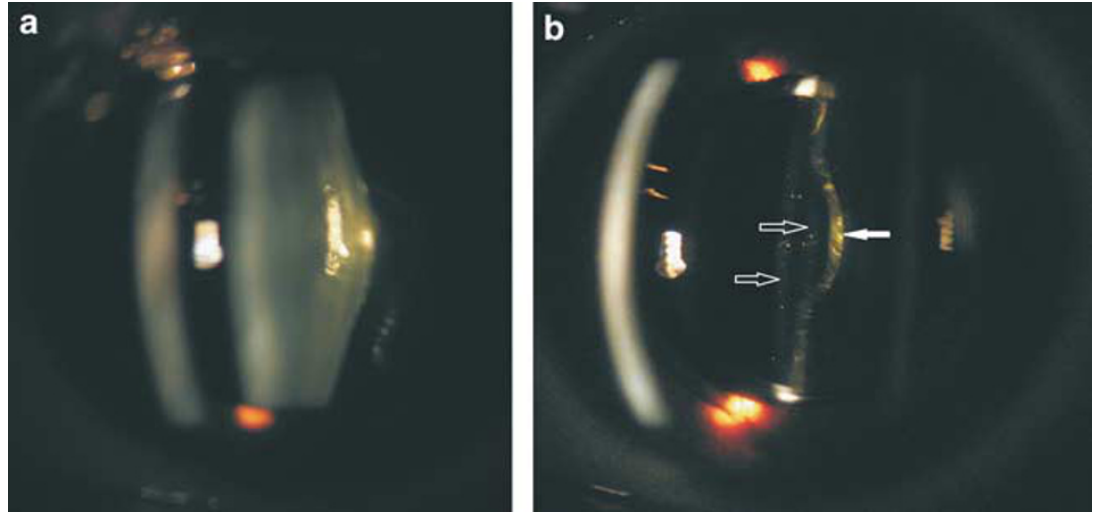

Figure 1 (a) Slit lamp photo of the patient with slit illumination showing the abnormal contour of the posterior surface of the lens and the opacity in the posterior pole. (b) Three months postoperative slit lamp photo showing the anterior and posterior surface of the IOL (empty arrows), and the posterior capsule (filled arrow). Notice the significant bulging of the posterior capsule centrally in the area corresponding to the lenticonus. 